\title{
Processamento da Cana-de-Açúcar: Efeitos sobre a Digestibilidade, o Consumo e a Taxa de Passagem ${ }^{1}$
}

\author{
Jane Maria Bertocco Ezequiel ${ }^{2}$, Mário Adriano Ávila Queiroz ${ }^{3}$, Rosemary Laís Galati ${ }^{4}$, \\ Ana Rosália Mendes ${ }^{4}$, Expedita Maria de Oliveira Pereira ${ }^{5}$, Cristian Faturi ${ }^{5}$, Virgílio Franco do \\ Nascimento Filho ${ }^{6}$, José Valmir Feitosa ${ }^{7}$
}

RESUMO - O objetivo neste trabalho foi estudar o efeito do tratamento alcalino da cana-de-açúcar com hidróxido de sódio (1,5 a $50 \%$ de $\mathrm{NaOH}$ ) sobre a digestibilidade total e o consumo de matéria seca das dietas experimentais e as taxas de passagem das canasde-açúcar. Foram utilizados quatro bovinos mestiços (Zebu x Holandês) alimentados com canas-de-açúcar in natura, hidrolisada, hidrolisada fenada e hidrolisada ensilada como fontes volumosas, constituindo $70 \%$ das dietas. O tratamento alcalino foi mais eficiente na fração fibra, proporcionando aumentos de pelo menos $45 \%$ na digestibilidade. Os aumentos de 25,0 e 16,7\% no consumo das dietas contendo as cana-de-açúcar hidrolisada (1,5\% PV) e hidrolisada fenada (1,4\% PV) provavelmente foram influenciados pela maior digestibilidade da fibra. Os valores estimados de taxa de passagem ruminal no ceco-cólon e o tempo de retenção em cada compartimento não diferiram entre as cana-de-açúcar in natura, hidrolisada e hidrolisada fenada. Entretanto, para a cana-de-açúcar hidrolisada ensilada, observaram-se as menores taxas (1,5 e 7,4\%/h) e o maior tempo de retenção (71,4 horas). Concluiu-se que o tratamento alcalino com hidróxido de sódio, com ou sem fenação, melhorou a digestão da fibra da cana-de-açúcar no trato digestivo total e proporcionou acréscimo do consumo de matéria seca da cana-de-açúcar hidrolisada, sem afetar a taxa de passagem. Entretanto, a posterior ensilagem pode não trazer esses benefícios.

Palavras-chave: bovinos, fibra, hidrólise, tratamento alcalino, volumoso

\section{Effects of Sugar Cane Processing on Digestibility, Intake and Rate of Passage}

ABSTRACT - Four crossbred bovines (Zebu x Holstein) fed in nature, hydrolyzed, hydrolyzed sugar cane hay and silage as roughage sources constituting $70 \%$ of the diets were used to study the effect of alkali treatment of sugar cane $(1.5 \%$ of $\mathrm{NaOH}$ at $50 \%$ ) on dietary total digestibility and dry matter intake and rate of passage of sugar canes. The fiber was the most influenced fraction by the alkali treatment and increased at least by $45 \%$ of digestibility. The increases of 25.0 and $16.7 \%$ on intake of hydrolyzed(1.5\% BW) and hydrolyzed sugar cane hay-based diets (1.4\% BW) were probably influenced by the higher fiber digestibility. The estimated values of ruminal and cecco-colon rate of passage and retention time in each treatment did not differ among in nature, hydrolyzed and hydrolyzed sugar cane hay-based diet, whereas the lowest rates (1.5 and 7.4\%/h) and highest retention time (71.4 hours) were observed for the hydrolyzed silage. It was concluded that alkali treatment with sodium hydroxide, with or without sugar cane hay, increased fiber digestion of hydrolyzed sugar cane in total tract and increased intake, without effect on passage rate. However, post ensilage of hydrolyzed sugar cane could not show effects.

Key Words: alkali treatment, bovines, fiber, hydrolyzis, roughage

\section{Introdução}

A crescente demanda de alimentos de origem animal para a população tem levado produtores e pesquisadores à busca por novas alternativas de alimentação para os animais. Os animais de grande porte, em especial os ruminantes, necessitam de duas grandes fontes de alimentação, o volumoso e o concentrado. No entanto, o valor desses alimentos repre- senta parcela significativa no custo de produção de carne e/ou de leite.

O fornecimento de cana-de-açúcar como suplemento volumoso no período de estiagem é uma das práticas mais interessantes, considerando-se a disponibilidade de forragem neste período crítico. Entre todas as gramíneas tropicais, a cana-de-açúcar detém a produção máxima, com aproximadamente 86 toneladas de MS/ha/ano (Franzolin Neto et al., 1989). As

\footnotetext{
${ }^{1}$ Projeto Financiado pela FAPESP.

${ }^{2}$ Docente do Departamento de Zootecnia da Faculdade de Ciências Agrárias e Veterinárias, Unesp/Jaboticabal. E.mail: janembe@fcav.unesp.br

3 Mestre em Zootecnia pela FZEA/USP, Doutorado na ESALQ/Piracicaba. E.mail: marioqueiroz@hotmail.com

${ }^{4}$ Doutoras em Zootecnia pela FCAV/Unesp.

5 Pós-graduandos em Zootecnia pela FCAV/Unesp.

${ }^{6}$ Pesquisador do CENA/USP, Piracicaba-SP.

${ }^{7}$ Estatístico, Doutor em Zootecnia pela FCAV/Unesp .
} 
principais desvantagens quanto ao seu uso são os teores baixos de proteína e de minerais, além de seu elevado teor de fibra, rica em lignina.

Tanto a cana-de-açúcar in natura quanto o bagaço de cana são essencialmente materiais de alto teor lignocelulósico. Portanto, a viabilidade de sua utilização requer o desenvolvimento de métodos de tratamento que promovam o rompimento da estrutura da fração fibrosa, para torná-la mais digestível (Burgi, 1985). Com essa necessidade, o tratamento da cana-de-açúcar com aspersão de $\mathrm{NaOH}$, a partir de dispositivo dosador acoplado à picadeira, seria uma alternativa.

De modo geral, o tratamento de volumosos com $\mathrm{NaOH}$ proporciona melhoria na digestibilidade, incremento na ingestão voluntária, aumento no consumo de água e prevenção da acidose. Andrade \& Fukushima (1994) trataram bagaço de cana com soluções alcalinas de $\mathrm{NH}_{4} \mathrm{OH}$ e observaram superioridade do $\mathrm{NaOH}$ em relação ao $\mathrm{NH}_{4} \mathrm{OH}$ em deslignificar o bagaço, elevando sua digestibilidade. Possivelmente esta superioridade se deva ao fato de o $\mathrm{NaOH}$ ser um alcali mais forte que o $\mathrm{NH}_{4} \mathrm{OH}$. A justificativa para o emprego de álcalis reside no fato de a lignina de gramíneas ser particularmente susceptível ao ataque hidrolítico dos mesmos, nas ligações covalentes do tipo éster entre a lignina e a parede celular (Van Soest, 1994).

Um animal consumindo $10 \mathrm{~kg}$ de MS/dia estará ingerindo aproximadamente $126 \mathrm{~g} /$ dia de sódio a partir do tratamento da cana-de-açúcar com o NaOH. O nível de $1,5 \%$ de $\mathrm{NaOH}$ a $50 \%$ no tratamento da cana-de-açúcar foi recomendado por Queiroz et al. (2000), visando economicidade e efetividade do tratamento alcalino.

O objetivo neste trabalho foi estudar o efeito do tratamento alcalino com hidróxido de sódio sobre a digestibilidade total, o consumo e a taxa de passagem de dietas contendo cana-de-açúcar nas formas in natura, hidrolisada, hidrolisada fenada e hidrolisada ensilada.

\section{Material e Métodos}

O experimento foi conduzido nas dependências da Unidade Animal de Estudo Digestivos e Metabólicos e na Granja Leiteira, ambos pertencentes ao Departamento de Zootecnia da Faculdade de Ciências Agrárias e Veterinárias da UNESP, Campus de Jaboticabal.

O trabalho foi composto por quatro tratamentos, distribuídos em dietas contendo:

CAN - cana-de-açúcar in natura - foi utilizada cana de $3^{\circ}$ corte, com adubação feita somente no plantio, em razão das boas características do solo, plantada no Campus da Faculdade de Ciências Agrárias e Veterinárias, Unesp/Jaboticabal, variedade RB825336;

CH - cana-de-açúcar hidrolisada - a mesma variedade do tratamento CAN foi picada e hidrolisada com $\mathrm{NaOH} 50 \%$ (1,5\% PV) no momento em que a forragem era cortada pelas facas da picadeira hidrolisadora HIDROCANA. No momento em que as facas da picadeira picavam a cana-de-açúcar, a válvula dosadora de $\mathrm{NaOH}$ promovia o gotejamento e a velocidade das facas a pulverização do $\mathrm{NaOH}$ sobre a cana-de-açúcar picada. Com o tratamento alcalino, o valor do $\mathrm{pH}$ da cana-de-açúcar elevava-se para 13 sendo seu controle realizado com fita de tornasol. Após 24 horas, o pH era medido novamente e, se estivesse próximo a 9, era fornecido aos animais.

FEN - cana-de-açúcar hidrolisada fenada logo após o mesmo tratamento de hidrólise, o material ficou exposto ao sol por aproximadamente 8 horas, disposto em camada fina (máximo $1 \mathrm{~cm}$ ) em terreno cimentado, até atingir $85 \%$ de matéria seca. Este ponto ficou caracterizado pela ausência de material com aspecto grudento e presença de material quebradiço e solto.

SIL - cana-de-açúcar hidrolisada ensilada logo após a hidrólise, o material foi compactado em silo tipo trincheira, que permaneceu fechado por 30 dias.

Foram utilizados quatro bovinos mestiços (Zebu x Holandês) com peso médio de $700 \mathrm{~kg}$, providos de cânula ruminal, recebendo dieta composta de volumoso e concentrado na relação 70:30 na matéria seca, com o objetivo de maximizar o efeito das canas-de-açúcar. Todos os animais ingeriram o mesmo concentrado, composto por $51,0 \%$ de milho em grão moído, $17,0 \%$ de soja em grão moída e 31,9\% de farelo de soja, totalizando $10,0 \%$ proteína bruta e 4,9\% de extrato etéreo, ambos na matéria seca. Na Tabela 1 encontra-se a composição bromatológica das canas-de-açúcar utilizadas nas dietas. $\mathrm{O}$ alimento foi fornecido duas vezes ao dia (7 e $18 \mathrm{~h}$ ) permitindo-se $10 \%$ de sobras.

A digestibilidade no trato gastrintestinal total foi estimada pela FDNi como indicador interno, utilizando a técnica de digestão in vitro por 144 horas. A porcentagem de FDNi foi calculada incubando-se 0,5 g de amostras das sobras das dietas e das fezes, de cada tratamento, utilizando-se saliva artificial e líquido ruminal na proporção 4:1, em único estágio de digestão, segundo o método de Tilley \& Terry (1963), descrito por Silva \& Queiroz (2002). Após a incuba- 
ção, os tubos foram colocados a $5^{\circ} \mathrm{C}$, para interromper parcialmente a digestão, e seus conteúdos foram quantitativamente transferidos para os copos de Berzelius $(600 \mathrm{~mL})$. Foram adicionados $50 \mathrm{~mL}$ de solução de detergente neutro e realizada a extração, conforme o método de Goering \& Van Soest (1970).

As coletas de fezes foram realizadas em quatro dias consecutivos, em quatro repetições, avançandose duas horas a cada horário $(2 ; 4 ; 6 ; 8 ; 10 ; 12 ; 14 ; 16$; 18; 20; 22 e 24 h), sendo as amostras compostas por animal e por repetição. O consumo de matéria seca das dietas experimentais foi relativo aos quatros dias correspondentes ao ensaio de digestibilidade.

A estimativa dos coeficientes de digestibilidade aparente da matéria seca (MS) foi feita segundo a fórmula:

Digestibilidade da MS do trato digestivo total (DMSTDT)

DMSTDT $=[1-(\%$ FDNi MS ingerida/\% FDNi MS fezes) ] *100

A estimativa do coeficiente de digestibilidade aparente da proteína bruta (PB), fibra em detergente neutro (FDN), fibra em detergente ácido (FDA), celulose (CEL) e da hemicelulose (HEM), como variáveis estudadas, pela fórmula:

Dvariável estudadaTDT $=100-[100 *(\%$ FDNi ingerido/\% FDNi fezes)*

(\% variável estudada nas fezes/\% variável estudada no ingerido)]

Os ingredientes da dieta, das sobras e das fezes foram pré-secos, quando necessário, em estufa de circulação e renovação de ar $\left(55^{\circ} \mathrm{C}\right)$ por 72 horas e processados em moinho tipo facas com peneira de crivos de $1 \mathrm{~mm}$. As amostras foram submetidas à análise de matéria seca, proteína bruta, fibra em detergente neutro, fibra em detergente ácido, celulose, hemicelulose e lignina, de acordo com as metodologias descritas por Silva \& Queiroz (2002).

Para determinação da taxa de passagem, as canas-de-açúcar in natura, hidrolisada, hidrolisada fenada e hidrolisada ensilada foram mordentadas com dicromato de sódio (Úden et al., 1980). As canas-deaçúcar mordentadas (100 g) foram adicionadas imediatamente antes da primeira alimentação do dia, via cânula ruminal. Os horários de coleta de amostras de fezes foram: 0, 3, 6, 12, 24, 36, 48, 72, 96 e 120 horas após a introdução do ingrediente mordentado no rúmen. As concentrações de cromo nas amostras de fezes e nas canas-de-açúcar mordentadas foram determinadas pelo EDXRF (fluorescência de raios X por dispersão de energia). Os espectros obtidos foram interpretados pelo aplicativo AXIL - Analysis of X-Ray Spectra by Interative Least-Squares (Van Espen et al., s/d) e, a partir dos raios X característicos, calcularam-se as concentrações. O modelo utilizado para determinar as variáveis da taxa de passagem foi o proposto por Grovum \& Williams (1973).

O delineamento experimental utilizado para a análise estatística das digestibilidades, do consumo de matéria seca, das taxas de passagem e dos tempos de retenção e de trânsito foi em blocos casualisados (animais), com quatro tratamentos e quatro repetições, sendo os dados submetidos ao programa GLM do Statistical Analyses Systems (SAS, 1995) e as médias, comparadas pelo teste Tukey a 5\% de probabilidade.

Tabela 1 - Composição bromatológica das canas-de-açúcar in natura ou hidrolisadas utilizadas nas dietas Table 1 - Chemical composition of in nature or hydrolyzed sugar cane in the diets

\begin{tabular}{|c|c|c|c|c|c|c|c|c|}
\hline $\begin{array}{l}\text { Volumoso } \\
\text { Roughage }\end{array}$ & $\begin{array}{l}\text { MS } \\
D M\end{array}$ & $\begin{array}{l}\mathrm{MO} \\
\mathrm{OM}\end{array}$ & $\begin{array}{l}\mathrm{PB} \\
\mathrm{CP}\end{array}$ & $\begin{array}{l}\text { FDN } \\
N D F\end{array}$ & $\begin{array}{l}\text { FDA } \\
A D F\end{array}$ & $\begin{array}{l}\text { Celulose } \\
\text { Cellulose }\end{array}$ & $\begin{array}{l}\text { Hemicelulose } \\
\text { Hemicellulose }\end{array}$ & $\begin{array}{c}\text { Lignina }^{1} \\
\text { Lignin }\end{array}$ \\
\hline Roughage & $\%$ & & & & $\begin{array}{l}\% \mathrm{MS} \\
\% D M \\
\end{array}$ & & & \\
\hline CAN (SUC) & 37,0 & 98,8 & 3,0 & 55,6 & 32,4 & 23,7 & 23,2 & 8,7 \\
\hline $\mathrm{CH}(\mathrm{HSC})$ & 38,0 & 91,0 & 2,5 & 47,3 & 30,6 & 23,8 & 16,7 & 6,8 \\
\hline FEN (HSCH) & 85,0 & 91,1 & 2,0 & 43,0 & 28,2 & 20,9 & 14,8 & 7,3 \\
\hline SIL (HSIL) & 31,4 & 90,2 & 1,6 & 43,2 & 37,6 & 25,2 & 5,6 & 12,4 \\
\hline
\end{tabular}

1 Lignina obtida por oxidação com permanganato de potássio.

CAN: cana-de-açúcar in natura; CH: cana-de-açúcar hidrolisada; FEN: cana-de-açúcar hidrolisada fenada; SIL: cana-de-açúcar hidrolisada ensilada.

${ }^{1}$ Lignin obtained by oxidation with potassium permanganate.

SUC: in nature sugar cane; SCH: hydrolyzed sugar cane; HSCH: hydrolyzed sugar cane hay; HSIL: hydrolyzed sugar cane silage. 


\section{Resultados e Discussão}

Os valores de digestibilidade da matéria seca, proteína bruta, fibra em detergente neutro, fibra em detergente ácido, celulose e hemicelulose das dietas no trato digestivo total encontram-se na Tabela 2.

Para todos os componentes nutritivos, foram observados valores de digestibilidade mais elevados $(\mathrm{P}<0,05)$ nas dietas que continham cana-de-açúcar tratada (CH, FEN ou SIL) em relação à cana-deaçúcar in natura (CAN). Oliveira et al. (2001) obtiveram média de 64,0\% de digestibilidade da matéria seca (MS) de seis variedades de cana-de-açúcar in natura, o que está próximo aos 58,6\% da CAN.

Com o tratamento alcalino, observou-se que o aumento na digestibilidade da MS foi de 36,8\% para a $\mathrm{CH}$ enquanto, para a FEN e SIL, de 26,0\%, em média. Avaliando a silagem de cana-de-açúcar tratada com 1\% de $\mathrm{NaOH}$, Andrade et al. (1999) observaram que o coeficiente de digestibilidade foi de $66,6 \%$ para a MS, enquanto para a FDN esse valor foi de $40,7 \%$. Alves et al.(2001) obtiveram valor de 54,84\% para a digestibilidade da MS da cana-de-açúcar in natura e, ao tratarem a cana-de-açúcar com 2 e $4 \%$ de $\mathrm{NaOH}$, os aumentos foram de 12,6 e $8,6 \%$, respectivamente.

O maior valor de digestibilidade protéica foi obtido quando a cana-de-açúcar foi submetida somente à hidrólise alcalina (74,3\%), observando-se que os processamentos adicionais (fenação e ensilagem) foram menos expressivos.
Queiroz (2001), ao estudar a degradabilidade ruminal da proteína das canas-de-açúcar in natura e submetidas a tratamento químico com $1,5 \%$ a $50 \%$ de $\mathrm{NaOH}$, observou que houve apenas solubilização protéica, com valores médios de $63,0 \%$ para a canade-açúcar in natura e 68,0\% para as canas-deaçúcar hidrolisadas. Verificaram ainda que as relações NIDN/N total e NIDA/N total não foram influenciadas pela hidrólise. Dessa forma, não havendo a possibilidade de incremento na digestibilidade da proteína bruta da cana-de-açúcar por meio da hidrólise, inferiu-se que os aumentos de 42,9; 32,7 e 16,1\% na digestibilidade das dietas contendo $\mathrm{CH}$, FEN e SIL foram resultantes do aumento na digestibilidade dos demais constituintes (milho em grão moído, soja em grão moída e farelo de soja). O maior aumento foi observado na dieta contendo $\mathrm{CH}$, ou seja, na cana-deaçúcar in natura submetida apenas ao processo de hidrólise. Na FEN, além da hidrólise, houve o processo de secagem ao sol, enquanto a SIL foi submetida à fermentação. Essas diferenças nos processos de obtenção dos volumosos também pode ter influenciado as digestibilidades. Sugere-se, portanto, um possível efeito associativo benéfico da cana-de-açúcar apenas tratada e do concentrado utilizado.

Alves et al. (2001) obtiveram aumentos de 8,6 e de 3,3\% na digestibilidade da proteína bruta das dietas quando a cana-de-açúcar foi hidrolisada com 2 ou $4 \%$ de $\mathrm{NaOH}$. As dietas eram compostas pela cana-deaçúcar hidrolisada e por $2 \mathrm{~kg}$ concentrado/dia. Esses

Tabela 2 - Digestibilidade da matéria seca (MS), proteína bruta (PB), fibra em detergente neutro (FDN), fibra em detergente ácido (FDA), celulose (CEL) e hemicelulose (HCEL) das dietas no trato digestivo total

Table 2 - Digestibility of dry matter (DM), crude protein (CP), neutral detergent fiber (NDF), acid detergent fiber (ADF), cellulose (CEL) and hemicellulose (HCEL) of the diets in total tract

\begin{tabular}{lcccccc}
\hline & MS & PB & FDN & FDA & CEL & HCEL \\
& $D M$ & $C P$ & NDF & ADF & CEL & HCEL \\
\cline { 2 - 6 } Dieta & \multicolumn{7}{c}{$\begin{array}{c}\text { Digestibilidade no trato digestivo total (\%) } \\
\text { Diet }\end{array}$} & Digestibility in total digestive tract (\%) \\
\hline CAN (SUC) & $58,6 \mathrm{c}$ & $52,0 \mathrm{c}$ & $29,4 \mathrm{c}$ & $26,3 \mathrm{~d}$ & $34,7 \mathrm{c}$ & $29,6 \mathrm{c}$ \\
CH (HSC) & $80,2 \mathrm{a}$ & $74,3 \mathrm{a}$ & $65,4 \mathrm{a}$ & $62,5 \mathrm{a}$ & $72,7 \mathrm{a}$ & $65,5 \mathrm{~b}$ \\
FEN (HSCH) & $75,4 \mathrm{~b}$ & $69,0 \mathrm{~b}$ & $55,3 \mathrm{~b}$ & $52,7 \mathrm{~b}$ & $62,7 \mathrm{ab}$ & $56,0 \mathrm{~b}$ \\
SIL (HSIL) & $72,5 \mathrm{~b}$ & $60,4 \mathrm{~b}$ & $50,5 \mathrm{~b}$ & $38,2 \mathrm{c}$ & $58,7 \mathrm{~b}$ & $94,5 \mathrm{a}$ \\
CV (\%) & 3,3 & 6,7 & 7,6 & 10,3 & 11,8 & 8,5 \\
\hline
\end{tabular}

Médias seguidas de mesma letra, na coluna, não diferem $(P>0,05)$ entre si pelo teste Tukey.

CV (\%): coeficiente de variação.

CAN: cana-de-açúcar in natura; CH: cana-de-açúcar hidrolisada; FEN: cana-de-açúcar hidrolisada fenada; SIL: cana-de-açúcar hidrolisada ensilada.

Means followed by the same letter, in column, did not differ $(P>0.05)$ by Tukey test.

CV (\%): coefficient of variation.

SUC: in nature sugar cane; SCH: hydrolyzed sugar cane; HSCH: hydrolyzed sugar cane hay; HSIL: hydrolyzed sugar cane silage.

R. Bras. Zootec., v.34, n.5, p.1704-1710, 2005 
aumentos estiveram associados ao evidente efeito da hidrólise e também ao aumento no consumo de MS.

A digestibilidade da FDN elevou 122,4; 88,1 e 71,8\% para a CH, FEN e SIL, respectivamente, em relação a CAN, observando-se que o melhor efeito do tratamento alcalino ocorreu para a $\mathrm{CH}$. Semelhantemente aos resultados obtidos para FDN, o tratamento alcalino proporcionou aumento na digestibilidade da FDA, o que pode ser atribuído à quebra das ligações lignocelulósicas, permitindo o ataque microbiano e, conseqüentemente, à melhor digestão da fração fibrosa das canas-de-açúcar hidrolisadas. A $\mathrm{CH}$ apresentou o melhor resultado para a digestibilidade da FDA, com aumento de $137,6 \%$, enquanto a ensilagem foi o processamento de menor efeito (45,2\%). Alves et al. (2001) também observaram que o tratamento alcalino com $2 \%$ de $\mathrm{NaOH}$ elevou a digestibilidade da FDN (23,8 vs $31,7 \%$ ) e da FDA (26,4 vs 33,5\%) quando comparada àquela obtida para a cana-de-açúcar in natura, embora em menor proporção.

O aumento na digestibilidade da celulose também foi mais expressivo para a $\mathrm{CH}$, seguida da FEN e SIL, com aumento de 109,5; 80,7 e 69,2\%, respectivamente, em relação à CAN. A digestibilidade da HCEL da dieta contendo SIL foi a mais influenciada, provavelmente em decorrência dos processos de hidrólise e de ensilagem. Houve aumento de 219,2; 44,3 e 68,7\% para as digestibilidades de CAN, CH e FEN, respectivamente. Uma hipótese para explicar este resultado seria a utilização dos açúcares presentes na HCEL, fragilizada pelo tratamento alcalino e pelos microrganismos presentes no processo de ensilagem. Esses açúcares estariam mais disponíveis à digestão enzimática intestinal, aumentando a digestibilidade no trato digestivo total da HCEL.

Quanto à composição bromatológica, também notouse que a HCEL foi a fração mais influenciada pela hidrólise, observando-se que o seu teor na CAN foi de 23,2\%, enquanto na CH, FEN e SIL sua redução foi de 38,9; 56,8 e 314\%, respectivamente; ou seja, além do efeito do tratamento alcalino, os processamentos posteriores também influenciaram a HCEL da cana-de-açúcar.

De modo geral, o tratamento alcalino influenciou positivamente a digestibilidade das frações fibrosas, proporcionando melhor aproveitamento da fibra da dieta, talvez disponibilizando mais energia para estímulo do crescimento microbiano, elevando o aporte de proteína para os intestinos.
O tratamento químico, especialmente com $\mathrm{NaOH}$, tem aumentado a digestão da CEL e HCEL, podendose enfatizar como benefícios do tratamento a solubilização da hemicelulose (Queiroz, 2001), a nãoredução da lignina com o tratamento (Klopfenstein \& Kraus, 1972) e o aumento na digestão da fibra, em virtude da quebra nas ligações entre lignina e hemicelulose ou celulose sem remoção da lignina.

Na Tabela 3 encontram-se os consumos de matéria seca das dietas. A CH e o FEN proporcionaram os maiores $(\mathrm{P}>0,05)$ consumos de $\mathrm{MS}$ em relação à CAN e SIL.

O aumento no consumo de MS das dietas contendo $\mathrm{CH}$ e FEN provavelmente foi influenciado pela maior digestibilidade da fibra (Preston, 1982; Allen, 1991; Mendonça et al., 2004), visto que a qualidade da FDN e da FDA variou com o tratamento da cana-deaçúcar, devendo estar relacionado ao rompimento das ligações químicas com a lignina (Klopfenstein, 1978).

A hidrólise alcalina seguida da fermentação ocorrida durante o processo de ensilagem não proporcionou aumento no consumo de MS quando comparada à CAN. A hidrólise alcalina pode ser positiva, pois o consumo da silagem de cana-de-açúcar in natura pode ser limitado, em decorrência da elevada produção de álcool etílico durante o processo de fermenta-

Tabela 3 - Consumo de matéria seca das dietas contendo as canas-de-açúcar in natura, hidrolisada, hidrolisada fenada e hidrolisada ensilada

Table 3 - Dry matter intake of diets containing in nature, hydrolyzed, hydrolyzed hay and hydrolyzed silage sugar cane-based diets

\begin{tabular}{lcc}
\hline & \multicolumn{2}{c}{ Consumo } \\
& \multicolumn{2}{c}{ Intake } \\
\cline { 2 - 3 } Dieta & Matéria seca $(\mathrm{kg} / \mathrm{dia})$ & $\mathrm{PV}(\%)$ \\
Diet & Dry matter $\left(\mathrm{kg}_{\text {day }}{ }^{-1}\right)$ & $\mathrm{BW}(\%)$ \\
\hline CAN (SUC) & $8,4 \mathrm{~b}$ & $1,2 \mathrm{~b}$ \\
$\mathrm{CH}($ HSC $)$ & $10,5 \mathrm{a}$ & $1,5 \mathrm{a}$ \\
FEN $($ HSCH) & $9,8 \mathrm{a}$ & $1,4 \mathrm{a}$ \\
SIL $($ HSIL) & $8,4 \mathrm{~b}$ & $1,2 \mathrm{~b}$ \\
CV $(\%)$ & 3,8 & 4,3 \\
\hline
\end{tabular}

Médias seguidas de mesma letra minúscula, na coluna, não diferem $(P>0,05)$ entre si pelo teste Tukey.

PV (\%): consumo em relação à percentagem do peso.

CV (\%): coeficiente de variação.

CAN: cana-de-açúcar in natura; $\mathrm{CH}$ : cana-de-açúcar hidrolisada; FEN: cana-de-açúcar hidrolisada fenada; SIL: cana-de-açúcar hidrolisada ensilada.

Means followed by the same small letter, in column, did not differ $(P>0.05)$ by Tukey test.

$B W$ : intake in relation to weight percentage.

CV (\%): coefficient of variation.

SUC: in nature sugar cane; SCH: hydrolyzed sugar cane; HSCH: hydrolyzed sugar cane hay; HSIL: hydrolyzed sugar cane silage. 
ção (Alcântara et al., 1989). Andrade et al. (2001a) observaram que a porcentagem de álcool etílico produzido na silagem de cana-de-açúcar in natura foi de 7,8\% enquanto a de ácido lático foi de 9,8\%. Ao tratar a cana-de-açúcar com $0,25 \%$ de $\mathrm{NaOH}$ e $0,5 \%$ de uréia, Andrade et al (2001b) observaram que essas porcentagens foram de 2,1 e 19,7\%, na mesma ordem, confirmando que a hidrólise alcalina possibilita que seja produzido ácido lático em detrimento do álcool etílico, possibilitando melhores consumos.

Comparativamente à FEN, havendo a necessidade de se armazenar a cana-de-açúcar para períodos com menor oferta de volumosos, a ensilagem de cana-de-açúcar hidrolisada poderia não ser o processamento mais vantajoso. Destaca-se, nesse caso, que a hidrólise seguida da ensilagem não melhorou o consumo da SIL, mas o tratamento alcalino, que diminui a produção de álcool etílico em favorecimento do ácido acético, possibilitaria melhor consumo. Os menores efeitos da hidrólise sobre as digestibilidades resultam em menores consumos de nutrientes digestíveis, podendo não atender às exigências nutricionais da categoria animal. Como implicação, seria necessária a associação da SIL com outra fonte volumosa, como a silagem de milho, além da utilização de concentrados de qualidade (Magalhães et al., 2004), o que poderia onerar a alimentação, diminuindo o benefício da hidrólise no caso da SIL.

Na Tabela 4 encontram-se os valores das estimativas de taxa de passagem ruminal (k1), taxa de passagem no ceco-cólon (k2), tempo de retenção retículo-ruminal (TRRR), tempo de retenção no cecocólon (TRCC), tempo médio de retenção(TMR=TRRR + TRCC) e tempo de trânsito (TT) das canas-deaçúcar estudadas. O TT é o tempo de latência para que o indicador apareça pela primeira vez nas fezes.

Tabela 4 - Valores de taxa de passagem ruminal (k1), taxa de passagem no ceco-cólon (k2), tempo de retenção retículoruminal (TRRR), tempo de retenção no ceco-cólon (TRCC), tempo médio de retenção (TMR) e tempo de trânsito (TT) das canas-de-açúcar in natura, hidrolisada, hidrolisada fenada e hidrolisada ensilada, mordentadas

Table 4 - Values of ruminal passage rate values ( $k 1)$, cecco-colon passage rate ( $k 2)$, reticulum-rumen retention time (RRRT), ceccocolon retention time (CCRT), average time of retention (MTR), transit time (TT) of in nature, hydrolyzed, hydrolyzed hay and hydrolyzed silage sugar cane, mordanted

\begin{tabular}{|c|c|c|c|c|c|c|}
\hline \multirow[t]{2}{*}{$\begin{array}{l}\text { Volumoso } \\
\text { Roughage }\end{array}$} & k1 & $\mathrm{k} 2$ & $\begin{array}{l}\text { TRRR } \\
R R R T\end{array}$ & $\begin{array}{l}\text { TRCC } \\
\text { CCRT }\end{array}$ & $\begin{array}{l}\text { TMR } \\
\text { MTR }\end{array}$ & $\begin{array}{l}\text { TT } \\
\text { TT }\end{array}$ \\
\hline & \multicolumn{2}{|c|}{$\% / \mathrm{h}$} & \multicolumn{4}{|c|}{ Horas (Hours) } \\
\hline CAN (SUC) & $2,6 \mathrm{a}$ & $17,0 \mathrm{a}$ & $40,1 \mathrm{~b}$ & $5,9 \mathrm{~b}$ & $46,0 \mathrm{~b}$ & $12,3 \mathrm{~b}$ \\
\hline $\mathrm{CHH}(S C)$ & $2,7 \mathrm{a}$ & $21,7 \mathrm{a}$ & $37,8 \mathrm{~b}$ & $4,7 \mathrm{~b}$ & $42,6 b$ & $8,6 \mathrm{~b}$ \\
\hline FEN (HSCH) & $2,3 \mathrm{ab}$ & 16,9 a & $43,8 b$ & $6,0 \mathrm{~b}$ & $49,8 b$ & $14,8 \mathrm{~b}$ \\
\hline SIL (HSIL) & $1,5 \mathrm{~b}$ & $7,4 \mathrm{~b}$ & $71,4 \mathrm{a}$ & $13,7 \mathrm{a}$ & $84,8 \mathrm{a}$ & 57,9 a \\
\hline CV (\%) & 20,0 & 19,7 & 25,7 & 19,2 & 23,1 & 43,0 \\
\hline
\end{tabular}

Médias seguidas de mesma letra, na coluna, não diferem $(P>0,05)$ entre si pelo teste Tukey.

CV (\%): coeficiente de variação.

CAN: cana-de-açúcar in natura; CH: cana-de-açúcar hidrolisada; FEN: cana-de-açúcar hidrolisada fenada; SIL: cana-de-açúcar hidrolisada ensilada.

Means followed by the same letter, in column, did not differ $(P>0.05)$ by Tukey test.

CV (\%): coefficient of variation.

SUC: in nature sugar cane; SCH: hydrolyzed sugar cane; HSCH: hydrolyzed sugar cane hay; HSIL: hydrolyzed sugar cane silage

A taxa de passagem no rúmen determina o fluxo de digesta pelo trato gastrintestinal, que, no caso de forrageiras tropicais, apresenta baixos valores, em virtude, principalmente do alto teor de fibras de baixa degradabilidade, provocando o efeito de repleção ruminal (Fernandes et al., 2003).

O TRRR representa o tempo em que o alimento permanece no rúmen sofrendo a ação dos microrganismos, favorecendo a fermentação ruminal, sendo uma variável inversamente correlacionada à taxa de passagem no rúmen (Grovum \& Williams, 1973; Preston, 1982), além de ser dependente do limite físico do animal (Jung \& Allen, 1995). Destaca-se que o elevado TRRR observado na SIL correspondeu ao aumento de 88,9 e 63,0\%, comparativamente à $\mathrm{CH}$ e FEN, respectivamente. Assim, o maior tempo de retenção, associado às menores digestibilidades, justificou o menor consumo obtido para SIL.

\section{Conclusões}

O tratamento alcalino com hidróxido de sódio melhorou a digestão da fibra da cana-de-açúcar, proporcionando maior consumo de matéria seca. 
A fenação da cana-de-açúcar hidrolisada pode ser uma alternativa viável, se houver a necessidade de armazenamento desse volumoso.

O maior tempo de trânsito da cana-de-açúcar hidrolisada ensilada não refletiu em melhores resultados, comparativamente às demais canas-de-açúcar tratadas.

\section{Literatura Citada}

ALCÂNTARA, E.; AGUilerA, A.; ELliOTT, R. et al. Fermentation and utilization by lambs of sugarcane harvested fresh and ensiled with and without $\mathrm{NaOH} .4$. Ruminal kinetics. Animal Feed Science and Technology, v.23, n.2, p.323-331, 1989.

ALLEN, M.S. Carbohydrate nutrition. The Veterinary Clinics of North America, v.7, n.2, p.327-340, 1991.

ALVES, J.B.; GODOY, M.M.; BERGAMASCHINE, A.F. et al. Digestibilidade da cana hidrolisada e in natura In: REUNIÃO ANUAL DA SOCIEDADE BRASILEIRA DE ZOOTECNIA, 38., 2001, Piracicaba. Anais... Piracicaba: Sociedade Brasileira de Zootecnia, 2001. CD-ROM. Nutrição de Ruminantes 6-0846.

ANDRADE, M.B.M.; FUKUSHIMA, R.S. Efeitos de diferentes tratamentos no bagaço de cana sobre a digestibilidade dos nutrientes.1. Digestibilidade in vitro. In: REUNIÃO ANUAL DA SOCIEDADE BRASILEIRA DE ZOOTECNIA, 31., 1994, Maringá. Anais... Maringá: Sociedade Brasileira de Zootecnia, 1994. p.514.

ANDRADE, J.B.; FERRARI JR., E.; BRAUN, G. Valor nutritivo de cana-de-açúcar tratada com hidróxido de sódio eadicionada de rolão de milho. In: REUNIÃO ANUAL DA SOCIEDADE BRASILEIRA DE ZOOTECNIA, 36., 1999, Porto Alegre. Anais... Porto Alegre: Sociedade Brasileira de Zootecnia, 1999. CD-ROM. Nutrição de Ruminantes. NUR 101.

ANDRADE, J.B.; FERRARI JR., E.; POSSENTI, R.A. et al. Valor nutritivo da silagem de cana-de-açúcar, cortada aos 7 meses de idade, tratada com uréia e adicionada de rolão de milho. In: REUNIÃO ANUAL DA SOCIEDADE BRASILEIRA DE ZOOTECNIA. 38., 2001, Piracicaba. Anais... Piracicaba: Sociedade Brasileira de Zootecnia, 2001a. CD-ROM. Nutrição de Ruminantes 6-0164.

ANDRADE, J.B.; FERRARI JR., E.; POSSENTI, R.A. et al. Valor nutritivo da silagem de cana-de-açúcar, cortada aos 7 meses de idade, tratada com $0,25 \%$ de hidróxido de sódio e 0,50\% de uréia e adicionada de rolão de milho. In: REUNIÃO ANUAL DA SOCIEDADE BRASILEIRA DE ZOOTECniA, 38., 2001, Piracicaba. Anais... Piracicaba:Sociedade Brasileira de Zootecnia, 2001b CD-ROM. Nutrição de Ruminantes 6-0261.

BURGI, R. Produção do bagaço de cana-de-açúcar (Saccharum sp L.) auto-hidrolisado e avaliação para ruminantes. 1985. 61p. Dissertação (Mestrado em Ciência Animal e Pastagens) - Escola Superior de Agricultura Luis de Queiroz, Universidade de São Paulo, Piracicaba, 1985.

FERNANDES, A.M.; QUEIROZ, A.C.; PEREIRA, J.C. et al. Cana-de-açúcar com diferentes ciclos de produção em três idades de corte. Revista Brasileira de Zootecnia, v.32, n.6, p.1778-1785, (suplemento 1), 2003.

FRANZOLIN NETO, R.; ZANETTI, A.M.; HERLING, V.R. et al. Efeito de diferentes níveis de dois compostos tamponantes sobre a digestibilidade de rações contendo bagaço de cana-de- açúcar hidrolisado como volumoso. Revista da Sociedade Brasileira de Zootecnia, v.18, n.5, p.456-461, 1989.

GOERING, H.K.; Van SOEST, P.J. Forage fiber analyses (apparatus, reagents, procedures and some application). Washington:USDA Agriculture Research Service, 1970. 20p. (Agriculture Handbook, 379)

GROVUM, W.L.; WILLIAMS, V.J. Rate of passage of digesta in sheep. British Journal of Nutrition, v.30, n.2, p.313-329, 1973.

JUNG, H.G.; ALLEN, M.S. Characteristics of plant cell walls affecting intake and digestibility of forages by ruminants. Journal of Animal Science, v.73, n.11, p.313-329, 1995.

KLOPFENSTEIN, T.J.; KRAUS, M.J. Chemical treatment of law quality roughages. Journal of Animal Science, v.35, n.2, p.418-422, 1972

KLOPFENSTEIN, T.J. Chemical treatment of crops residues. Journal of Animal Science, v.46, n.3, p.841-848, 1978.

MAGALHÃES, A.L.R.; CAMPOS, J.M.S.; VALADARES FILHO, S.C. et al. Cana-de-açúcar em substituição à silagem de milho em dietas para vacas em lactação:desempenho e viabilidade econômica. Revista Brasileira de Zootecnia, v.33, n.5, p.1292-1302, 2004.

MENDONÇA, S.S.; CAMPOS, J.M.S; VALADARES FILHO, S.C. et al. Consumo, digestibilidade aparente, produção e composição do leite e variáveis. Revista Brasileira de Zootecnia, v.33, n.2, p.481-492, 2004.

OLIVEIRA, B.Y.S.; ALVES, J.B.; BERGAMASCHINE, A.F. et al. Desempenho do bovinos terminados em confinamento, com diferentes volumosos. In: REUNIÃO ANUAL DA SOCIEDADE BRASILEIRA DE ZOOTECNIA, 38., 2001, Piracicaba. Anais... Piracicaba:Sociedade Brasileira de Zootecnia, 2001. CD-ROM. Nutrição de Ruminantes 6-0844.

PRESTON, T.R. Nutritional limitations associated with the feeding of tropical forages. Journal of Animal Science, v.54, n.4, p.877-884, 1982.

QUEIROZ, M.A.A.; OLIVEIRA, M.D.S.; BETT, V. Digestibilidade ïn vitro da matéria seca da cana-de-açúcar hidrolisada. In: CONGRESSO DE INICIAÇÃO CIENTÍFICA DA UNESP, 12., 2000, São José do Rio Preto. Resumos... São Paulo: Pró-Reitoria Unesp, 2000. p.273.

QUEIROZ, M.A.A. Digestibilidade total e degradabilidade ruminal da cana-de-açúcar in natura, hidrolisada com hidróxido de sódio e hidrolisada fenada. Jaboticabal: Universidade Estadual Paulista, 2001. 58p. Monografia (Graduação em Zootecnia) - Universidade Estadual Paulista, 2001.

STATISTICAL ANALYSeS SYSTEMS - SAS. Language guide v.6, 3.ed. Cary: 1995. 530p.

SILVA, D.J.; QUEIROZ, A.C. Análise de alimentos: métodos químicos e biológicos. 3.ed. Viçosa, MG: Universidade Federal de Viçosa, 2002. 235p.

UDÉN, P.; COLUCCI, P.E.; Van SOEST, P. J. Investigation of chromium, cerium and cobalt as markers in digesta. Rate of passage studies. Journal of Science Food and Agriculture, v.31, n.2, p.625-638, 1980.

Van ESPEN, P.; JANSSENS, P.; SWENTER, S. 1 AXIL -X-ray Analysis software: users manual. Bebelux:Packlard, s.d. 72p.

Van SOEST, P.J. Nutritional ecology of the ruminant. 2.ed. Ithaca:Cornell University Press, 1994. 476p. 